Forum $2021 \cdot 36: 331$

https://doi.org/10.1007/s12312-021-00968-3

Online publiziert: 6. August 2021

(c) Springer Medizin Verlag GmbH, ein Teil von

Springer Nature 2021

\section{LOVE your Skin - gesunder Sonnenspaß ohne Reue}

Bayerische Krebsgesellschaft e.V.
Weil Vorsorge besser ist als Nachsorge, erweitert die Bayerische Krebsgesellschaft ihre Aktivitäten in Sachen Sonnenschutz und Hautkrebsprävention.

Was im richtigen Umgang mit der Sonne zu beachten ist, darüber informiert die Bayerische Krebsgesellschaft seit März 2021 mit der Aufklärungskampagne „Love your Skin“ zum Thema Sonnenschutz und Hautkrebsprävention. Und das auf sehr niedrigschwellige Art und Weise, nämlich an den Orten, an denen Sonnenschutzprodukte gekauft werden - in Supermärkten und Drogeriemärkten. Interessierte können sich schon beim Kauf von Sonnenschutzprodukten über den richtigen Umgang mit der Sonne informieren. Produktaufsteller und Hinweisschilder an den Regalen mit Sonnenschutzmitteln sind mit dem LOVE your SKIN-Logo und einem QRCode zur Aktion versehen. Mithilfe eines Smartphones gelangen Interessierte auf eine Infoseite der Bayerischen Krebsgesellschaft und erfahren dort, was sie aktiv tun können, um die Sonne ohne Reue genießen zu können und ausreichend geschützt zu sein. Denn Vorsorge ist immer besser als Nachsorge und für eine gesunde Haut kann jeder etwas tun. Die Aufklärungskampagne wurde möglich in Kooperation mit der Emil-Kießling $\mathrm{GmbH}$. Wir freuen uns, dass die Aktion ab 2022 auch von anderen Landeskrebsgesellschaften mitgetragen wird, um eine breitere Bevölkerung zu erreichen.

Vor allem Kinder sollten besonders gut vor zu intensiver Sonnenstrahlung geschützt werden, da bei ihnen die natürliche Hautbarriere und der körpereigene Schutzmechanismus noch nicht völlig ausgebildet ist. Häufige Schäden durch UV-Strahlen im Kindesalter können später zu Hautkrebs führen, darum sollte für Kinder immer ein hoher Lichtschutzfaktor gewählt werden. Um Eltern und Erzieher im richtigen Umgang mit der Sonne zu schulen, führt die Bayerische Krebsgesellschaft das Projekt "SunPass - gesunder Sonnenspaß für Kinder" in Kindergärten durch und konnte jüngst neue Förderer und Kooperationspartner gewinnen, um das Projekt weiter auszubauen.

\section{Informationen zu Love Your Skin}

https://www.bayerische-krebsgesellschaft.de/presse/projekte/love-your-skin/

\section{Informationen zu SunPass}

https://www.bayerische-krebsgesellschaft.de/presse/projekte/sunpass/

\section{Korrespondenzadresse}

\section{Cornelia Gilbert}

Bayerische Krebsgesellschaft Nymphenburger Straße 21a 80355 München, Deutschland gilbert@bayerische-krebsgesellschaft.de

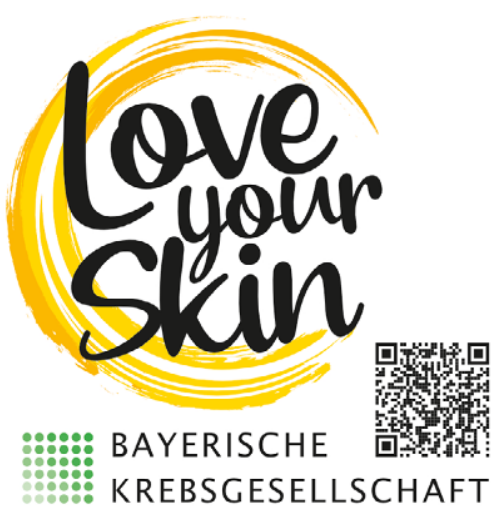

KREBSGESELLSCHAFT

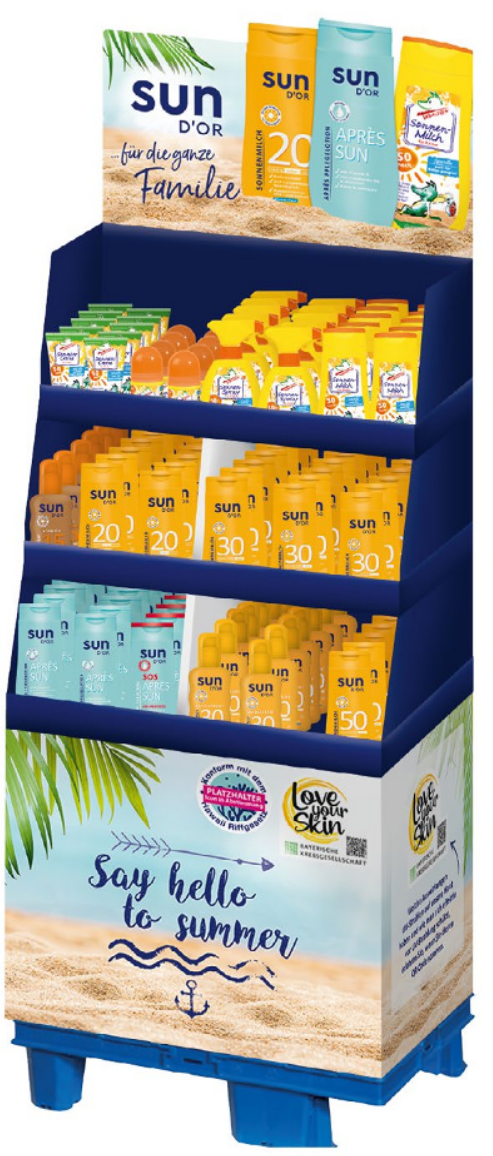

